\title{
Research on Mechanical Engineering Graduation Design of University
}

\author{
Yang Anjie \\ College of Mechanical Engineering \\ Henan Institute of Engineering \\ Zhengzhou, China \\ yanganjie163@163.com
}

\author{
Yang Janwei \\ College of Mechanical Engineering \\ Henan Institute of Engineering \\ Zhengzhou, China \\ ymww10@sina.com
}

\begin{abstract}
Graduation design is the key practice step in the teaching for undergraduate students and reflects the level of teaching and training of the university. This paper discusses the characteristics of mechanical engineering of undergraduate majors and analyses the main problems of the university graduation design. By studying some of the important steps of graduation design process, such as select the topics, open thesis proposal, guideline, paper review and defense, the methods and measures for improving the quality of graduation design have been put forward.
\end{abstract}

Keywords-Mechanical engineering; graduation design; research; quality improvement

\section{INTRODUCTION}

Graduation design is the most important teaching link that is training program to undergraduate students of the college. It is a comprehensive knowledge application of basic course, specialized basic courses and specialized courses that a student has learned in four years. It is also the main methods for the students to learn the scientific research, design way and training scientific research ability. It is also the important graduation and degree qualification basis of the student. Graduation design quality directly reflects the level of teaching and the quality of personnel training. It is the important measure evaluation content of education quality and school running benefit. Mechanical engineering undergraduate professional class consists mainly of mechanical design manufacture and automation, vehicle engineering, thermal energy and power engineering, material processing and control. For those students, the completion of graduate design should meet the following requirements: (1) Consolidate knowledge learned before, to make it systematic and comprehensive.(2) Encourage students for basic experience ability to design calculations, engineering drawing, experimental methods, data processing, files editing, the words express, documents indexing, computer and reference book application. The basic study methods should be mastered preliminary. The students usually learned the software included: Microsoft office, Auto-CAD, Pro.E, UG, Solidworks, etc. (3) Cultivate independence thinking, serious and practical style of work, establish to study hard, the courage to explore, the development innovation and cooperation with other people's consciousness should be trained.
To meet these requirements, it was very important which studied the quality of the graduation design process control. There are many scholars have studied and achieved some results [1-3]. But it is seldom discussion for mechanical engineering graduate design[4]. This paper discusses the graduation design characteristics of mechanical engineering of undergraduate majors. By researching some of the important steps of graduation design process, such as select the topics, open thesis proposal, guideline, paper review and defense, the constructive comments and solution for improving the quality of graduation design have been put forward.

\section{The Problems in GraduAtion Design}

With the constant enlargement of the scale of undergraduate enrollment, the structural proportion of teachers and students become imbalance, as well as the graduation practice and design fee is becoming serious inadequacy, cause the quality of graduation design is declining, copy phenomenon is often seen. At present, affecting the quality of graduation design mainly has the following several aspects:

\section{A. The Influence of the Student Future}

Graduation design is arranged the last semester of grade four in university. But in the final of the seventh semester, many students began to look for a job, even with the employers signed an agreement, and there are quite more students participated in graduate student exam. At the eighth semester students will take part in the postgraduate reexamination and the part of the students to join work, so the genuine reassurance students for graduation designed is not much, unless they are recommend the graduate student or and $\mathrm{PhD}$.

\section{B. Lack of Attention by Students}

Many students think that graduation design is for the teacher to do, so graduation design through the line is ok. Obtaining good results is cumbersome and uselessness, many employers don't care for graduation design is excellent.

\section{The Problems of School Management and Teachers}

The number of students which one teacher guide are too much. Our school set up not more than 10. Most universities require a student given one topic. In fact, if a teacher make 10 
subject to the guidance of graduation design, higher quality of work is very difficult. In addition, the graduation design expenditure, pay, the steering would influence the quality of graduation design. Also, individual teacher responsibility heart is not strong, no care the students and follow one's own inclination.

\section{Work Procedures and Result Distribution}

The procedures are unreasonable, and topics not fully execute two-way choice, as well as guidance teacher instead of student statement to answer questions. The proportion scores of the guiding teacher, the marking teacher and defense score are unreasonable. Some schools is $30: 20: 50$, some schools is $30: 30: 40$.

\section{GRAduAtion DESIGN Procedures}

My school graduation design working procedure is: (1) to complete the graduation design (Thesis) problem declaration form in the fifteenth week of seventh semester; (2) to release topics and arrangement student to select prior to the seventeenth weeks of seventh semester; (3) the teacher met with students before eighteenth weeks of seventh semester, to give the students of graduation design (Thesis) task book; (4) to write the proposal, foreign literature translation, literature review by students before two weeks in the eighth semester; (5) to complete the midterm review eighth week in eighth semesters; (6) students completed design (Thesis) and submitted to teachers in fifteenth weeks, so guiding teacher reviewers evaluating it; (7)three grade defense during 17th18th week; (8) to review and publish the results ..

\section{SEVERAL Key LiNKS IN GRADUATION DESIGN}

\section{A. The problem of selecting topic}

The quality of selecting topics is the important factor that affects the quality of graduation design. Selecting topics is the first step for graduation design. The common topic types for mechanical engineering graduate design were given below:

(1)Engineering design topics, including the mechanical structure design and process, mechanical and electrical integration.

(2)Theoretical analysis and experimental research topics.

(3)Software development topics.

(4)Summarize topics.

(5)Comprehensive topics.

Graduation design topics should be consistent with the training objectives and business requirements. The first, selected topic should belong to the professional knowledge scope, covering as much as possible of the professional courses and professional courses in the basic theory and basic skills, so that students can receive comprehensive training. In fact, for mechanical engineering undergraduate specialty, such as mechanical design \& manufacturing and automation, vehicle engineering, thermal energy and power engineering, material processing and control, the range of choices is quite broad, such as machine tool design, design of mining machinery, food and light industry machinery design, automobile and tractor design and experiment, the engine design and experiment, new material and new industrial research, and so on. Secondly, selection should have a certain depth, workload, difficulty should be moderate, undergraduate students through the efforts can be completed, and can cultivate consciousness of engineering and innovation spirit to the students. we presents a topic which is " the design of hand starting device for single-cylinder diesel engine " for the students in the 2012, but some teachers regarded it is small and simple, its workload and difficulty is not great. Then in fact it is proved to be just perfect. Students used knowledge of spiral transmission, a ratchet mechanism, overrunning clutch and gear transmission in the design, and knowledge of the kinematics, mechanics verification calculation, metal materials, the engine structure and working principle were utilized. The basic design drawing software of AUTOCAD and Solidworks was put to use. It can be said to mobilize almost the main course, and tested the students creative thinking. Thirdly, it should be have a complete laboratory equipment, instrumentation and data security.

The design topic should be combined with the actual production. The research topics should be the practical scientific research background. The software topics should have practical value. To promote the scientific research project into the graduation design topics is encouraged for the teacher, this will create a" combat" training opportunities for students. Selecting topic should be one student to get one topic, the topics of students must be not same from each other. But if several students with one task, each student should have a different topic, as a teacher to develop the topic is " $\times \times \times$ combined lathe design", and will be divided into several subtasks: one is " $\times \times \times$ combined lathe drive mechanism design", another is " $\times \times \times$ combined lathe body design", and the other is " $\times \times \times$ combined lathe control system design", and so on. The summarize topics should be used with caution, software development pay attention to the prevention and cure of plagiarism or results cannot be real application. These topics cannot run hastily or its loopholes appeared one after another during the defense. There are similarity topics, such as " based on ANSYS finite element analysis for $\times \times \times$ "," $\times \times \times$ "can be created to seven or eight topics, but if these same type topics are chosen by the students, they learn and copy from each other, so the design has become a specific form, not be one student to get one topic. Some topics are suitable only for curriculum design.

Selecting topics should be developed as soon as possible. The students have selected the topics and get the reference data before the holidays. Then they lay a foundation in holiday to complete the thesis. It executes two-way choice module to select topic[6]. The two-way choice selection mode which can prevent students choose to not interested topic direction, as well as some teachers get all poor students of the class of, both sides have autonomy. But in the actual operation there are still some problems, such as students are more willing to choose some teachers who requires not rigorous or some teachers are leadership. Some topics have high research value, but it is difficulty students to do, so they afraid of it or for employment reasons but rather than choosing.

In view of the above question, to consider topics can accord to the following several aspects. (1) One student selects 
one topic which is different from the other as far as possible, so that you can avoid students copied or reference from each other in graduation design. They can truly think from the view point of design, to achieve practice the ability to solve practical problems. (2) Selecting topics should be link to the actual production and engineering application. This is conducive to mobilizing the enthusiasm of the students, because it is they really do the work, and they will take the initiative to learn familiar with the production of the actual situation, to enable students to actively participate in the studying job. (3) The topics which involves a number of areas or large workload and a certain depth may be appropriate to increase the students together to complete the task, so that to ensure the students to accomplish the task after efforts in graduation design work time, but noted that the division of labor, and make the final graduation thesis content repetition rate must be reduced. (4) The teacher or leader neglected guidance in the past time should be limited to teaching the number of the students.

\section{B. The problem of the opening topics}

In order to improve the teaching quality of graduation design, opening topics defense should be insisted, its purpose was given below:

(1) It can be found early the graduate design topic can meet the professional requirements or not through the opening links, or can complete the task or not on time, or the content is cover such basic knowledge of the entire specialty or not.

(2) Through the implementation of the opening segment can also strengthen the students consulting the documents and materials, extensive information ability, cultivating students' questioning, develop experiment research method and design, scientific experiment and test, the data processing and analysis, experimental report writing, thesis ability, but also for the students' written and oral representations of the ability training, implement and strengthen the cultivation of students' innovative ability and effective means.

The opening of the specific requirements: we asked students before opening reply, according to the standard writing of the opening report, literature review ( 3000 words), foreign literature translation (3000 words). In the opening time, students must hold the teacher signed the opening report and other related data to report. The main report survey data preparation, design objectives, requirements, technical route and achievements form, task decomposition, the complete contents and time distribution, existing problems, students are required to account for 10 minutes, and then the panel according to the students' self-reported and opening report and other text, the graduation design topic is the specialty cultivation objectives and requirements and finish the thesis design feasibility assessment, and the graduation design topic design breadth, depth, appropriate degree, key and difficulty, put forward the specific amendments, the respondent group study, the task of local adjust, even for correction.

Literature review is not just a simple data stack, should include the issue of history, the review of research in contrast, as well as the study of development. The comprehensive description and evaluation of the article is made up of the system to consult with the selected topics related to domestic and foreign literature, collect, arrange, processing. In the review of literature, to reflect the subject directly related to the domestic and foreign research results, the latest advances in research, dynamic, frontier problems, especially in recent years, the latest achievements and development trend, also want to point out the subject further problems to be solved. Foreign literature translation must be related to the project materials and is the latest research results.

\section{Graduation design guidance problem}

The graduation guidance process is the key to success for graduation design.

(1)The First of all is to construct graduation design teaching team. Teachers should have the mid-level and above titles, and should be used to bring the old and new method for the cultivation of young teachers. To ensure quality, we should strictly control the number of students per teacher guidance. Teachers should not only with solid theoretical knowledge, but also has a wealth of experience in engineering practice. For no engineering background working experience of young teacher, missing is the experience of engineering practice. Young teachers should focus on cultivating engineering practice ability;

(2) The teacher is the first person responsibility for the graduate design of the whole process. Teachers should according to the plan, according to the requirements of carefully finished guide link, according to the mission book and the opening report to plan. Guide teachers should often communicate with the students. The teacher and student meeting not less than two times every week in our school, each time not less than 2 hours. In the content arrangement, should be combined with the specialized characteristics, make full use of school resources such as experimental tools, equipment and technology information, and to coordinate and guide students to the relevant enterprises and research institutions to visit. Teachers must fully mobilize the enthusiasm and initiative of students, emphasizing the practicality and creativity. The instructor must tackle crucial problem for guidance, teach students in accordance with their aptitude, can't be wrong in principle

(3) The format of graduation design or thesis is to meet the requirement. The number of words, typesetting, and charting, engineering drawings must be standard and specification

\section{Graduate design evaluation, trial and reply}

Teacher is the first person responsibility for the whole process of a graduate design. Teachers should seriously review the design specifications, drawings, and thesis. Teachers have the right to not recommend the students to participate in graduation design which do not seriously and do things carelessly or avoidance guidance or not completed all phases of graduation design task or absent as well as a serious violation of discipline of learning. Only the students which the teachers agree can join the graduation defense. Then the students will prepare the PPT. 
The students' graduation theses must be blind trial by the respondent groups of 1-2 members before reply. They should examine carefully review, fill the review comments and ratings in" graduation design (Thesis) review form", and propose $3 \sim 5$ of the problem to the defense committee.

The respondent is the last session of the graduate design work in, and is an important means of the quality for a comprehensive inspection and assessment of the graduation design. Strict reply will help students to establish good style of study, promote students to do graduate design. Our implementation is three level defenses, namely the university defense, department defence and teaching and research section defense. To participate in the Department of Defense shall not be less than the number of the total number of students $10 \%$, and the total number of students attending $1 \%$ recommended to participate the university defense.

The students which the teachers agreed to participate in the defense should prepare PPT which involves the thesis structure and the design result of content. The reply, each student respondent readme time 10-15 minutes, answer questions 10- 15 minutes. The student questions were recorded in the process of reply and were summarized. When the respondent is completed, all the respondent group members should give the graduation performance to each student.

Graduation design performance by the guiding teacher ratings, reviewers score, the respondent group score is composed of three parts, the three part of the ratio of $3: 3: 4$. Comprehensive evaluation of achievements by the excellent (100-90), good (89-80), medium (79-70), pass(69-60), fail given. Graduation design ( Thesis ) achievement finally by the Department of Defense Committee approved. The author thinks that teachers score and reviewers score ratio should not be the same, guide the teacher to the score proportion should be larger than the reviewers score for more reasonable. The students were defined for failing should be carefully. Evaluation must Comply with the standards and strict requirements. The ratio of excellent paper should be controlled strictly in the professional a total number of $15 \%$ or less. In order to ensure the impartiality of defense, the Department of the Ministry may invite external unit of experts consisting of the respondent group.

\section{E. Design of supervision and inspection}

It must pay attention to process management to ensure its quality because the graduation design lasted longer [7]. The office of academic affairs and department or teaching and research section shall be responsible for the organization early, mid-term and late examination stages. The mid-term examination is the examination of the key link, take the Department of comprehensive inspection and school checks combined mode, focus on examination of graduation design work, the title of the report, foreign language translation, the teachers guidance work of the difficulties and problems, and take effective measures to solve them. The student for poor work attitude, unfinished schedule or the thesis have significant problems is given the" yellow card" warning, and ordered to teachers and students together to formulate rectification measures. In order to ensure the impartiality of defense, the Department of the Ministry of defense in may invite external unit of experts consisting of the respondent group.

\section{CONCLUSION}

The graduation design is the teaching content in a university, and is also the key content to improve the student overall quality and the innovation ability. The content is not only a essential practice training independently, but also an important synthesis reorganization about knowledge in the school. To improve the graduation design work, the key is to want to accomplish "five place", i.e., understanding reaches the position, funding in place, teachers in place, students and management in place. In addition, the elimination all kinds of interference of students are the stage of students' ideological and political work focus before to do graduate design. Strict reply will help students to establish good style of study, promote students to do graduate design. A correct understanding of the importance of graduation design will be helpful to guarantee and improve the quality of teaching and to achieve the input of qualified personnel requirements for the community.

\section{REFERENCES}

[1] GAO Sheng-zhe ,ZHANG Li-fei. A Study about the Graduation Design on the Information and Computing Science Specialty[J]. Journal of Hunan University of Science and Engineering , V0l. 28No. 4 ,Apr. 2007,pp66-67;

[2] Yang Xin-le, Guo Ren-ning, Yu Jing-mei. The problem analysis of graduation practice design and method research for improving quality[J]. .china modern education equipment. V01.95 No.7,2010,p140142.

[3] Wang Hui-Li ${ }^{1}$, Qin Si-Feng ${ }^{2}$, Jiang Rong-Bing. Integration of graduation design and employment in civil engineering, OPEE 2010 - 2010 International Conference on Optics, Photonics and Energy Engineering, Wuhan, China ,2010, Article number 5508040, PP60-63.

[4] Wu Yan-Wen, Zhang Kun-Ming. Reference knowledge service module designing for the graduation design, Proceedings of the Sixth International Conference on Machine Learning and Cybernetics, ICMLC 2007, Hong Kong, China, DOI:10.1109/ICMLC.2007.4370884,pp 42064210

[5] Dong Jian. Problems and countermeasures of graduation design (thesis) of chemical engineering specialty[J].china modern education equipment. V0l.139 No.3,2009,p57-59.

[6] TIAN Boshi,LIU Shaohua. Study on the new rise of the university graduate design problems andthe measurement proposed[J]. Journal of Zhoukou Normal University. Vol.28 No.5, Sep.2011,P66-68. 